\title{
Microbiology Susceptibility Test Code
}

National Cancer Institute

\section{Source}

National Cancer Institute. Microbiology Susceptibility Test Code. NCI Thesaurus. Code C87945.

A character or string that represents the short code name of the microbiology susceptibility assessment. 